\title{
Reduced fetal movements
}

\author{
Alexander Heazell \\ From Stillbirth Summit 2011 \\ Minneapolis, MN, USA. 6-8 October 2011
}

The association between a reduction in fetal movements (RFM) and stillbirth has been noted for at least 450 years. This was formalised from the 1970s onwards in a series of studies that noted the increased incidence of stillbirth and FGR in women presenting with RFM, which in some cases preceded intrauterine fetal death by several days. Interpretation of the literature relating RFM to stillbirth and FGR is complicated by differences in studies' definitions of RFM and FGR [1]. Nevertheless, the association between RFM and stillbirth remains, irrespective of the definitions used. Recently, the Auckland Stillbirth Study confirmed that women who had a RFM were 2.4 times (95\% CI 1.29-4.35) more likely to have a late stillbirth [2], which is strikingly similar to a UK-based study which found a 3-fold increase in stillbirth after one presentation with RFM [3]. RFM, FGR and stillbirth are thought to be related by placental insufficiency, with RFM representing fetal compensation to restriction of nutrients and oxygen in utero $[4,5]$. This hypothesis is supported by evidence of abnormal placental structure and amino acid transport in women with RFM, even in the absence of a small-for-gestational age fetus [6].

Despite the association between RFM and stillbirth, RFM is frequently suboptimally managed clinically. Of 422 stillbirths reviewed in a confidential enquiry, $16.4 \%$ of cases had suboptimal care related to RFM, including: not communicating the importance of RFM to mothers and a failure to act on RFM [7]. Reasons for clinicians' behaviour have been explored by two related questionnaire studies, one in the UK and one in Australia and New Zealand. Both of these studies found significant variations in the definitions of RFM applied to clinical practice and varied knowledge of the association between RFM, FGR and stillbirth. As a consequence clinical management of women with RFM varied significantly, with cardiotocography being used in $80-90 \%$ of cases and ultrasound assessment

\footnotetext{
Correspondence: Alexander.Heazell@manchester.ac.uk
} University of Manchester, UK of fetal growth, liquor volume and umbilical artery Doppler in approximately $20 \%$ of cases $[8,9]$.

Due to the association between RFM, FGR and stillbirth, ultrasound assessment of fetal growth, liquor volume and umbilical artery Doppler may be useful screening tests to identify placental insufficiency [10]. Norwegian studies have suggested that asking women to be more aware of fetal movements did not increase the number of attendances with RFM. Importantly, the implementation of an associated quality-improvement programme was associated with increased use of ultrasound, but a reduction of stillbirth from $4.2 \%$ to $2.4 \%$ [11], strongly suggesting that appropriate identification of, and intervention following, RFM may decrease the incidence of stillbirth. The management of RFM may be improved by more sensitive tests to specifically identify placental dysfunction, including measurement of placentally-derived factors such as human placental lactogen or placental growth factor [12,13].

The use of RFM as a screening tool for stillbirth prevention needs to be developed; it has the advantages that it is free and does not significantly increase the burden on the antenatal service. However, the best management protocol after women present with RFM has yet to be determined. To date there have been no randomised controlled trials of the management of RFM, despite calls from the World Health Organisation to improve the quality of evidence regarding stillbirth prevention [14]. Therefore, a highquality trial is needed to evaluate whether intervention (delivery) directed by appropriate investigations after RFM can reduce the incidence of late stillbirth, without significantly increasing maternal and perinatal morbidity.

\section{Published: 28 August 2012}

\section{References}

1. Heazell AE, Froen JF: Methods of fetal movement counting and the detection of fetal compromise. J Obstet Gynaecol 2008, 28:147-154.

2. Stacey T, Thompson JM, Mitchell EA, Ekeroma A, Zuccollo J, McCowan LM: Maternal Perception of Fetal Activity and Late Stillbirth Risk: Findings from the Auckland Stillbirth Study. Birth 2011, 38:311-316. 
3. O'Sullivan O, Stephen G, Martindale EA, Heazell AE: Predicting Poor Perinatal Outcome in Women who Present with Decreased Fetal Movements - A Preliminary Study. Journal of Obstetrics and Gynaecology 2009, 29:705-710.

4. Maulik D: Doppler velocimetry for fetal surveillance: Adverse perinatal outcome and fetal hypoxia. New York, Springer-Verlag;Maulik D 1997:349.

5. Warrander $L K$, Heazell $A E$ : Identifying placental dysfunction in women with reduced fetal movements can be used to predict patients at increased risk of pregnancy complications. Med Hypotheses 2011, 76:17-20.

6. Warrander LK, Greenwood SL, Sibley CP, Jones RL, Heazell AEP: Reduced fetal movements are associated with significant changes in placental structure and function. Arch Dis Child Fetal Neonatal Ed 2011, 96:Fa56.

7. Confidential Enquiry into Stillbirths and Deaths in Infancy: 8th Annual Report, 1 January-31 December 1999. London, Maternal and Child Health Research Consortium 2001

8. Heazell AE, Green M, Wright C, Flenady V, Froen JF: Midwives' and obstetricians' knowledge and management of women presenting with decreased fetal movements. Acta Obstet Gynecol Scand 2008, 87:331-339.

9. Flenady V, MacPhail J, Gardener G, Chadha Y, Mahomed K, Heazell A, Fretts $R$, Froen F: Detection and management of decreased fetal movements in Australia and New Zealand: a survey of obstetric practice. Aust N Z J Obstet Gynaecol 2009, 49:358-363.

10. Froen JF, Tveit JV, Saastad E, Bordahl PE, Stray-Pedersen B, Heazell AE, Flenady V, Fretts RC: Management of decreased fetal movements. Semin Perinatol 2008, 32:307-311.

11. Holm Tveit JV, Saastad E, Stray-Pedersen B, Bordahl PE, Flenady V, Fretts R, Froen JF: Reduction of late stillbirth with the introduction of fetal movement information and guidelines - a clinical quality improvement. BMC Pregnancy Childbirth 2009, 9:32.

12. Warrander LK, Kroll J, Greenwood SL, Sibley CP, Jones RL, Heazell AEP: Placentally-derived Factors may be used to Predict Poor Pregnancy Outcome in Reduced Fetal Movements. Arch Dis Child Fetal Neonatal Ed 2011, 96:Fa12.

13. Benton SJ, Hu Y, Xie F, Kupfer K, Lee SW, Magee LA, von Dadelszen P: Can placental growth factor in maternal circulation identify fetuses with placental intrauterine growth restriction? Am J Obstet Gynecol 2012, 206(2):163.e1-7.

14. Haws RA, Yakoob MY, Soomro T, Menezes EV, Darmstadt GL, Bhutta ZA: Reducing stillbirths: screening and monitoring during pregnancy and labour. BMC Pregnancy Childbirth 2009, 9(Suppl 1):S5.

doi:10.1186/1471-2393-12-S1-A10

Cite this article as: Heazell: Reduced fetal movements. BMC Pregnancy and Childbirth 2012 12(Suppl 1):A10.

\section{Submit your next manuscript to BioMed Central and take full advantage of:}

- Convenient online submission

- Thorough peer review

- No space constraints or color figure charges

- Immediate publication on acceptance

- Inclusion in PubMed, CAS, Scopus and Google Scholar

- Research which is freely available for redistribution

Submit your manuscript at www.biomedcentral.com/submit
Biomed Central 